\title{
Trabalho artesanal e trabalho industrial como elementos de sociabilidade, subjetividade e tragédia em "A mão esquerda", de Roniwalter Jatobá
}

Angela Maria Rubel Fanini ${ }^{1}$

Adriana Cabral dos Santos ${ }^{2}$

Este artigo se propõe a analisar o texto "A mão esquerda", do escritor brasileiro Roniwalter Jatobá, à luz da temática trabalho e tecnologia, que se vincula ao grupo de pesquisa da Anpoll Linguagem, Enunciação e Trabalho. O trabalho e a tecnologia são condições essencialmente humanas e pertencem, em parte, às condições materiais de existência do homem. Desde as priscas eras, o homem procura alterar o seu entorno a fim de promover sua subsistência, procurando dominar e controlar a natureza, objetivando sobreviver. Essa eterna luta com o meio natural se dá a partir do trabalho associado entre os homens e da produção de tecnologias. Nesse processo, o homem passa da condição de animal a ser social, criando para si uma "segunda natureza" que advém do trabalho e da tecnologia.

Esse pensamento foi suficientemente explorado e analisado por vários antropólogos e para este artigo valemo-nos da obra de Engels (1990), para quem o trabalho é condição ontológica, ou seja, o homem só se constitui como ser social a partir do trabalho, diferenciando-se dos animais. O teórico alemão considera, inclusive, a mão como a primeira ferramenta do ser humano, que lhe possibilita se diferenciar dos animais, interagir com o meio e, sobretudo, criar outras ferramentas que estendam as capacidades humanas de modificar o meio ambiente. O uso continuado da mão e do movimento de pinça serviu para liberar a boca: daí advém a constituição da verbalização da fala interior. Trabalho, tecnologia e linguagem são vocações humanas e vão constituindo o ser social em interação com o meio e entre si. Embora Engels advogue a centralidade do trabalho na ontologia do ser social, percebe que a linguagem está associada à ação laboral, sendo também constituinte do humano. Esse processo material da alteração do ambiente para sobreviver vem acompanhado da linguagem.

O homem, objetivando criar condições materiais de existência, não o faz sem método, planejamento e reflexão. O terreno material das condições reais

\footnotetext{
${ }^{1}$ Doutora em teoria da literatura e professora da Universidade Federal Tecnológica do Paraná (UFTPR), Curitiba, PR, Brasil. E-mail: rubel@utfpr.edu.br

${ }^{2}$ Doutoranda na UFTPR. E-mail: adrianacabral2000@yahoo.com.br
} 
de existência está articulado ao terreno das ideias, em um processo ininterrupto de interação. Outro autor que vê essa articulação é Lukács (1980), para quem o trabalho é da ordem material, sendo, porém, a partir dele que o homem manifesta sua capacidade de planejamento, sociabilidade e subjetividade. O trabalho, para o teórico húngaro, é a protoforma social, sendo orientado por uma teleologia em que nitidamente se entrelaçam a questão material e a imaterial. O pensador enfatiza que é por meio da linguagem que o homem vai amadurecendo a sua capacidade de planejamento na ação laboral. Esta não é desprovida de reflexão no âmbito da linguagem. Assim, trabalho e linguagem adquirem também fundamental importância na constituição do homem enquanto ser criativo e que modifica o seu entorno. Além desses teóricos que advogam a centralidade do trabalho, associado à linguagem, na constituição do ser social, há uma farta bibliografia acerca desse assunto, sobretudo oriunda da sociologia do trabalho.

No campo da crítica e dos estudos literários não temos material suficiente que explore o tema trabalho e linguagem na literatura brasileira. Este artigo, como já mencionado, foi produzido a partir de um grupo de estudos que visa entender como ocorre a formalização discursiva literária sobre essa temática. A pesquisa objetiva ver como os trabalhadores do imaterial, ou seja, do trabalho simbólico, que visa refletir, reproduzir em parte, refratar, problematizar o mundo material, conformam suas narrativas e seus personagens no mundo do trabalho e da tecnologia. Para este artigo, tendo-se um limite de espaço, focalizamos apenas um texto de Roniwalter Jatobá.

Esse escritor, em boa parte de sua obra, tem recriado o mundo material do trabalho, apontando a importância e a centralidade do trabalho na vida e na lida das personagens. O discurso literário aqui é percebido como signo verbal que toma significação a partir da realidade sócio-histórica em que se insere. Não é entendido enquanto uma realidade autônoma, desvinculado de suas coordenadas históricas. Embora apresente especificidades formais e de gênero, o seu significado só pode ser apreendido em interação com o meio material e intelectual de onde parte. $\mathrm{O}$ texto literário, embora tenha uma autoria e essa autoria confira a ele um estilo próprio, também é um produto social na medida em que se faz a partir de outros discursos sociais e mantém com a realidade de sua época uma relação orgânica. Aqui, advogamos uma teoria materialista da linguagem, tendo por base o teórico Bakhtin (1986), para quem o signo verbal significa somente na interação social, endereçando-se sempre para as réplicas futuras, respondendo ao já dito e ao interlocutor futuro que possa objetá -lo, contrapor-se a ele. 
Também para Bakhtin, o signo verbal reflete e refrata a realidade, em um movimento de vinculação e autonomia. Novos contextos surgem e também novas palavras para os apresentar, representar, recriar ou deformar. A relação entre as palavras e as coisas é complexa e não monocausal. A partir dessa perspectiva materialista e simbólica sobre a linguagem literária, procuraremos perceber como nosso escritor, a partir do texto em tela, organiza a sua visão sobre o trabalho e a tecnologia, tendo em vista o contexto histórico imediato (década de 1970 no Brasil, mais especificamente a cidade de São Paulo e a fábrica mecanizada em contraposição ao espaço do lar, Nordeste rural e trabalho artesanal) e as outras vozes (discurso bíblico, discurso do trabalho na fábrica, discurso sobre o trabalho artesanal) que adentram o texto para trazer certa significação para nossa temática. Aliando contexto imediato trazido por certos discursos dentro do texto e contexto remoto, advindo da representação de vozes seculares, procuraremos perceber como nossa temática vai sendo construída e reconstruída no texto.

No interior dessa abordagem, importa destacar também, além da especificidade da história do trabalho no Brasil, a concepção de história que entendemos fundamentar a perspectiva desse artigo. Da mesma forma que consideramos a pluralidade de vozes discursivas a constituir o texto, assim entendemos a realidade enquanto multiplicidade de acontecimentos, e a história não como modelo universal e linear, baseada no progresso e cientificismo, e que homogeneíza o tempo e se impõem sobre todos, em todos os lugares. A própria dinâmica do atual mundo do trabalho no Brasil, que comporta atividades laborais tão diversas, vem nos mostrar que a modernidade e seus processos tecnológicos não eliminaram o trabalho braçal, nem o artesanal (e, infelizmente, também não o trabalho escravo) e que, portanto, convivem formas contraditórias de trabalho no contexto de desigualdades brasileiro.

Na obra de Jatobá, o trabalho do artesão, mais antigo e primitivo, instaura-se, então, como uma resistência ao trabalho assalariado e alienado na fábrica, e, embora haja um certo desprestígio na sociedade tecnológica em relação ao trabalho manual, é ele que se apresenta como capaz de restituir ao personagem principal, Natanael, sua identidade de trabalhador e a condição de pertença ao lugar de origem. Tanto a São Paulo das grandes indústrias como o Nordeste brasileiro, alheio em grande medida às promessas tecnológicas, compõem, destarte, o atual contexto do trabalho em nosso país em sua complexidade e contradições.

O texto narra, em primeira pessoa, a trajetória solitária da personagem Natanael, vindo de cidade pequena do Nordeste brasileiro para São 
Paulo, movido pelo desejo de trabalhar na indústria mecanizada urbana, dominar a maquinaria de produção em série e ganhar dinheiro. Na cidade grande, consegue um emprego tal qual idealizara, com carteira assinada em uma grande indústria. Passa à segunda fase, ou seja, a do treinamento para operar a maquinaria. Vê-se embevecido diante da máquina e aí faz inúmeras considerações sobre a superioridade da produção industrial em série em relação à fraca produção artesanal. Esta pertence à realidade da qual viera, pois seu pai, Elias, é proprietário de uma ferraria artesanal. Para sua infelicidade, não consegue dominar a máquina, a prensa, que lhe mutila a mão - daí o título, "A mão esquerda". Inutilizado para o trabalho fabril urbano, retorna à casa do pai para voltar a trabalhar no âmbito artesanal que tanto desmerecera ao chegar à cidade grande. O resumo, no entanto, não atinge a grandiosidade do texto, visto que ficamos no nível da fábula e não da trama, ou seja, não conseguimos passar, na totalidade, ao leitor, o como se constrói essa narrativa. Só a leitura do texto pode demonstrar a sua literariedade. Procuraremos, minimamente, trazer para a análise o nível formal de altíssima qualidade literária que conforma a obra. Entretanto, sabemos que só a leitura do texto pode dar a real dimensão literária da tessitura do texto para quem ora nos lê.

O discurso narrativo para o teórico da linguagem Bakhtin (1988) é de suma importância visto que estiliza o plurilinguismo social, abrigando muitas vozes e se instituindo em um discurso sempre indireto, na medida em que o contexto do narrador enquadra as falas dos outros. Essas falas podem estar ligadas diretamente às personagens da narrativa ou ainda podem se constituir na estilização de vozes sociais de variados campos e objetos como o direito, a história, a Bíblia, a ciência etc.. O texto narrativo é sempre uma recriação de falas sociais, concretas, que circulam na sociedade.

O texto bíblico é bastante recuperado pelo discurso literário em variados romances, contos e poemas da literatura brasileira. Roniwalter Jatobá também se vale desse discurso, agenciando-o para o interior de sua narrativa, sobretudo, quando denomina suas personagens. Os nomes escolhidos têm uma significação bastante grande na trajetória de vida das personagens. Iniciemos pela personagem Elias, pai do protagonista. Se recuperarmos o texto bíblico, teremos que Elias foi profeta do Reino do Norte, nos reinados de Acabe e do seu filho Acazias. A vida do profeta Elias girou em torno do conflito entre a religião do Senhor e a de Baal. Sua missão consistia em levar os israelitas a reconhecer sua apostasia e reorientá-los à fidelidade ao Deus de Israel.

A maneira corajosa de o profeta Elias falar ao rei Acabe e denunciar a impiedade de Israel fez dele um profeta exemplar, e a pessoa mais 
adequada daquela época para ser um modelo precursor de Jesus Cristo. A personagem Elias, no conto, é um ferreiro fiel à sua profissão, família e lugarejo. Não se vê seduzido pela aventura de sair de seu local de nascimento e deixar sua profissão. É ele que acolhe o filho quando este retorna de uma jornada infrutífera em que buscara uma alternativa, mas da qual volta sem êxito. Permanece no seu local, fiel à sua tradição.

Já o filho Natanael deseja outra realidade, indo para São Paulo em busca de melhores condições de existência. Renega o local em que nascera. Seduz-se pelo trabalho fabril, desmerecendo o trabalho artesanal que ocupara o pai durante toda a sua vida. Em excerto, podemos perceber o entusiasmo de Natanael por esse novo cenário: "Aí vendo a máquina, a prensa, como viva na minha frente, parecendo gente de corpo, de alma, a máquina que fazia o trabalho de mil Elias, meu pai, ferreiro, parado e lento Elias, bem comparado" (Jatobá, 1979, p. 23). Percebe-se aí que se imputa à maquina algo que lhe é estranho, pois é dotada de vida, e com ela o protagonista pretende interagir. Não percebe que a relação é despersonalizada, de obediência e submissão aos ditames técnicos. Deseja o novo, quer apropriar-se da máquina. Entretanto não se adapta a esse novo meio, pois não alcança o entendimento da lógica da fábrica, do trabalho alienado, da despersonalização da atividade mecânica que tenta assimilar. Na labuta com a máquina, objetivando dominá-la, é por ela dominado, tendo seus dedos amputados.

A perspectiva de Natanael é positiva: não enxerga o dolo do processo alienante no qual está inserido. Por não enxergar a faceta negativa, não se protege, sendo vitimado. No discurso bíblico, no Evangelho de João, apresenta-se Natanael como um conhecedor das escrituras e como alguém que vivia segundo o costume farisaico. Diz-se dele que era "um israelita em quem não havia fraude". Natanael não consegue entender a lógica de um ambiente em que o operário, por mais que consiga operar a máquina, com destreza e boa vontade, ainda assim pode não atingir seus objetivos. É puro e nele não há fraude, mas na fábrica essas características não são eficazes, pois impera a lógica da máquina, e esta se utiliza dos operadores como acessórios. Inverte-se a lógica, visto que, aí, a máquina sobressai em relação ao humano.

Após ser maneteado, volta ao seu local de origem uma vez que lá poderá exercer a profissão de ferreiro junto ao pai em uma comunidade artesanal em que o homem opera e domina a maquinaria. Na fábrica, em São Paulo, o trabalho alienado e estranhado; já no Nordeste, no pequeno vilarejo de onde partiu, o trabalho artesanal e dominável. Natanael, em sendo aquele em que não há dolo, também não consegue entender o que 
é o dolo, não atingindo, em consequência o entendimento dos perigos da maquinaria. Talvez aí também haja certo saudosismo do autor em relação ao ambiente da cidade pequena, do trabalho artesanal, da comunidade, da prevalência das relações humanas e um distanciamento em relação à metrópole, à fábrica, ao trabalho mecânico e mecanizado uma vez que neste cenário o protagonista só conhece e vivencia perdas e danos. Os próprios nomes bíblicos remetem a um mundo rural, de artesão, pescadores e pastores.

Na narrativa, São Paulo é formalizada a partir de uma linguagem descritiva em que ruas, edifícios, transporte urbano, fábrica e multidões vão surgindo em detalhes realistas. Já a pequena cidade de onde vem Natanael é pouco descrita e visualizada. Aí impera um cenário vago e parcamente descrito em que as relações pessoais e familiares se sobressaem. Há foco no local do trabalho artesanal com o manuseio do ferro e do fogo, criando artefatos, e nessa criação há também a diversão. Somente nesse cenário é que há possibilidade de o trabalho ser um meio de sociabilidade, de subjetividade e de recreação para o trabalhador. Na passagem seguinte, quando do retorno de Natanael, o narrador monta o cenário da ferraria e do lugarejo a esperar por ele. Ali há alegria e produção:

Natanael já vem quase chegando. Mais tarde, não vai ter ninguém naquela hora acordado, mas o massacre daquela bigorna vai encher o silêncio da noite de um som alegre de chegada acordando meio mundo:

Mãe vai dizer: Elias vai dormir!

Ele vai responder: não, o repique na bigorna, a brincadeira de repicar no ferro do homem aqui e Natanael, meu filho, logo vai recomeçar (Jatobá, 1979, p. 24).

Nota-se pela linguagem com que é construído esse cenário que ele tende a um local difuso, vago, em que nada é descrito de forma detalhista e realista. Isso se justifica porque aí não há estranhamento para o narrador. Tudo lhe é familiar. Nada precisa ser apropriado pela linguagem detalhista. São Paulo é já de outra ordem. Lá tudo é novo, mas, por mais que a linguagem tente apoderar-se desse cenário, ele se mantém alheio ao personagem que dele migra ao final da narrativa, visto que ali só encontrara a tragédia. Linguagem e descrição se opõem a linguagem e narração. ${ }^{3}$

\footnotetext{
3 Essa oposição tomamos de Lukács (1968), para quem há distinção entre linguagem descritiva própria de narrativas realistas - vinculadas à estética de fim de século XIX, em que se apresenta um mundo estranho e estático às personagens -, e linguagem narrativa em que perduram a ação e a interação entre as personagens, em um movimento dinâmico em que vão se constituindo e se alterando nessas articulações.
} 
Parece não haver diálogo possível entre esses mundos, embora eles convivam no presente como alternativas possíveis, apesar da reconhecida supremacia da sociedade tecnológica. Isso se comprova pelo retorno do filho pródigo ao lar paterno após a perda dos sonhos, das expectativas, da esperança e de parte do corpo. Aqui também se tem uma intertextualidade bíblica. O pai acolhe-o e voltam ambos a trabalhar na atividade artesanal. Em vez da máquina, a bigorna em brasa, visto que é esta que lhe confere uma identidade ${ }^{4}$ no lugarejo. No excerto a seguir, temos o término do conto, em que, em linguagem poética, em versos, o narrador resume a saída e a volta do filho pródigo:

Ferreiro Natanael onde andou teu corpo?

Sei que andou andou

Prensista Natanael onde andou tua mão?

Sei que andou andou Homem

Natanael onde andou tua mão?

Sei que andou andou

Homem Natanael onde andou teu sonho?

Sei que andou andou

Ferreiro, Prensita, Homem Natanael, onde andou tua vida?

Desandou, desandou

E Elias, teu pai, Elias Ferreiro, esperando, de longe, grita:/ Filho Natanael, pois retoque e repique este ferro em brasa na bigorna tua (Jatobá, 1979, p. 24).

Percebe-se que, nesse trecho, a profissão de ferreiro, ou seja, daquele que forja o ferro em brasa, é que perdura e dá uma identidade e uma possibilidade de vida a Natanael. Já a de prensista, que tentara aprender na fábrica, é algo negativo que faz sua vida desandar. Aqui também parece haver outra temporalidade e espacialidade, em que valores universais são reforçados. A narrativa insiste na valorização da

4 Sennett (1998), sociólogo americano, estuda as diferenças entre o capitalismo taylorista-fordista e o toyotista. Naquele ainda há associação, possibilidade de resistência e formação de uma identidade para o trabalhador, já que este permanece por muito tempo em um mesmo emprego. No capitalismo toyotista, a desagregação, a terceirização e a mudança de função e espaço causam um insulamento do operário, impedindo-o de se coletivizar. Entretanto, no conto, embora o protagonista esteja dentro de uma fábrica taylorista-fordista, mantém isolado, pouco compartilhando com os demais. O trabalho no espaço da fábrica não possibilita a construção de uma narrativa para Natanael, na interação com a máquina e com os demais. A mão desnecessária, esquerda, sucumbe à máquina. A máquina, além de indecifrável, é também inoperável diante da imobilidade das mãos de Natanael, acostumado à perfeição do trabalho artesanal na bigorna. Aí sim, na ferraria, ele adquire uma identidade entre os seus, que são testemunhas de seu trabalho. Identidade e trabalho só se associam na atividade artesanal. 
produção de artefatos a partir do metal e do fogo, elementos ${ }^{5}$ que nos remetem a uma história de longa duração do homem na sua árdua luta por sobrevivência, recuando a períodos iniciais da formação do homem, mas que se atualizam ainda hoje nas formas do trabalho artesanal, comum a muitas regiões do Brasil contemporâneo e modernizado. Longe se está do ambiente da fábrica com tecnologia mecanizada cujo funcionamento o trabalhador não entende.

O uso do fogo e do metal nos remete a narrativas míticas tal qual a de Prometeu, que rouba o fogo divino para dar aos homens a fim de que possam construir seus aparatos técnicos. Jatobá traz para o interior narrativo essa intertextualidade, construindo assim, juntamente com o discurso bíblico também agenciado, uma narrativa que recupera uma temporalidade de longa duração, distanciando-se de seu contexto imediato e atualizando-a, embora este também constitua a narrativa, como já referido. Há um movimento pendular do texto entre um contexto imediato estranho ao protagonista e outro, remoto, difuso, da casa e ferraria do pai, que deita raízes em uma história de longa duração, recuperando o discurso prometeico e o bíblico. Aquele é estranhado; este é familiar. Lá a despersonalização; aqui a identidade. De volta ao lar, apesar de mutilado seu corpo, revigora a sua alma e redescobre o seu lugar. Na ferraria, a importância do pertencimento ao lugar, ao trabalho. O domínio sobre a bigorna, em contraposição à inaptidão no uso da máquina na fábrica.

Outro procedimento narrativo importante no conto refere-se ao foco narrativo, visto que é bastante complexo, sendo em primeira pessoa (protagonista Natanael) e simultaneamente desdobrando-se em terceira pessoa, quando a personagem distancia-se de si, vendo-se e narrando-se como se fosse outro. Nesse distanciar-se, utiliza-se do presente atemporal e do pronome de tratamento "você". Este tanto serve para transformar a si mesmo em personagem, percebendo-se distanciado, denominando-se de você, testemunhado as próprias ações e narrando-as, quanto tem a função de generalizar a narrativa, como se ela pudesse acontecer a qualquer um, englobando a todos os que leem o conto. Distancia-se de si, do caso particularizado de Natanael e alcança certo universal, na medida em que o seu personagem pode ser tomado por um tipo social. A narrativa é específica,

\footnotetext{
${ }^{5}$ Leroi-Gourhan, antropólogo de bases estruturalistas materialistas, apresenta, em texto que trata da história de longa duração do desenvolvimento do homem, os vários períodos e suas especificidades tecnoeconômicas, demonstrando que o desenvolvimento e a inovação tecnológicas sempre foram uma constante na vida do ser humano, em embate com o meio natural e com os outros seres. O fogo, o metal, a inovação tecnológica, a violência, a divisão social e a alimentação baseada em vegetal e animal são constantes e milenares na história do homem (Leroi-Gourhan, 1964, p. 147-168).
} 
tem um cenário, personagens e linguagem próprias, mas transcende a condição individual do protagonista, generalizando-se à medida que narra sonhos, fracassos, retornos, esperanças, sofrimentos humanos, relação paternal e filial, familiaridade da vizinhança. A exemplo desse foco narrativo que se endereça a um você cujas funções são de testemunha e, ao mesmo tempo de partícipe da narrativa, tem-se:

Você, parado, olhando as rodas de gente observa os passos dos homens neste começo de noite e o movimento da rua, lhe xingam por atrapalhar o rebuliço na calçada apertada, você nem liga e só chega mais pra perto do meio-fio dando passagem (Jatobá, 1979, p. 17).

Essa construção, a um só tempo, distanciada de si, mas que de si parte, permite à personagem a reflexão sobre suas ações, generalizando-as na medida em que vê em vários transeuntes a si mesmo, transeuntes que poderão ter destino e desfecho parecidos. São os tantos milhares de operários na grande indústria paulista da década de 1970 advindos de regiões pobres do país. No trecho seguinte, há esse movimento do particular ao geral, remetendo ao contexto imediato histórico brasileiro que se acha presente na fábula, reconhecendo-se o novo cenário fabril da década de setenta e a migração nordestina para o Sudeste e a difícil adaptação na metrópole:

Pra você tudo aquilo por ora é importante, parece ser, depois você descobre que existe na calçada do outro lado da rua um homem parado, calado, que olha o ônibus, ai ele vai se aproximando devagar, [...] vai se esforçando em carregar a mala com a mão direita. A mão esquerda, você vê, aparece dentro das suas vistas como uma volumosa mancha branca. A mancha, agora, cresce dentro destes olhos teus. No homem: existe uma história, uma linguagem que é parecida com a sua, uma magreza na face que é magreza sua, e você se sente como se fosse ele. E assim é (Jatobá, 1979, p. 18).

O título do conto, "A mão esquerda", é altamente significativo, visto que a mão é, segundo vários antropólogos, a primeira ferramenta do homem na sua labuta pela sobrevivência. No trabalho de ferreiro que Natanael exerce junto à oficina doméstica do seu pai Elias, a mão é o instrumento que opera outros instrumentos. Por anos aprendeu o ofício de ferreiro e suas mãos mantiveram-se intactas, laboriosas, forjando o ferro em brasa e criando e produzindo artefatos e coisas. Já em São Paulo, na fábrica, a mesma mão tenta aprender o ofício, mas é mutilada. O corpo e a mente, no trabalho artesanal, estão em sintonia, pois o homem domina o processo técnico. Já na fábrica, o corpo dissocia-se da mente e a máquina impõe uma racionalidade alheia ao operário. A mão tenta obedecer à máquina e já não é mais governada pela mente, ocorrendo o desastre. Natanael não fora capaz de compreender essa sujeição à máquina. Foi preciso a máquina agir sobre seu 
corpo para que ele percebesse a sua submissão. Entretanto, com a máquina produzem-se muito mais artefatos que com a bigorna artesanal. Natanael, em um primeiro momento admira-se com isso, desprezando o trabalho do pai. Aqui também vê-se outra temporalidade, ou seja, a da máquina e não do homem, no trabalho artesanal, em que a produção é lenta, pois obedece ao ritmo do humano e de suas possibilidades e limitações físicas. Na passagem seguinte, percebe-se a dissociação entre mente, mão e máquina, esta já se apoderando do corpo do operário.

Fico lembrando a mesa da prensa pintada de tinta recente, azul, o molejo dela no sobre e desce e minha mão que ficou parada como mão de morto, mão de morto pois que não veio no pensamento da cabeça aquela vontade e ligeireza de puxar a mão, fiquei na frieza de um homem morto, a mão recebeu a força das toneladas de peso, ainda vi a cor do sangue (Jatobá, 1979, p. 18).

E em outra passagem, Natanael, ainda seduzido pela maquinaria, não entendendo a sua lógica e sentindo-se menor que ela, culpa-se pelo desastre:

E foi passando na cabeça o meu choro, o sangue melando a máquina, o azul dela, fui sentindo vergonha, não me veio um tico de nada de ódio da prensa, da prensa que me deixou com tocos de dedos, um homem aleijado, inutilizado como dizem por aí, não, não senti raiva cega da máquina, só da minha fraqueza, do meu medo, do descuido, do choro, essa mão, agora, pois vê, pesada e quieta como se não parecesse minha (Jatobá, 1979, p. 19).

\section{Considerações finais}

A leitura focada no trabalho artesanal e industrial nos leva a perceber que Jatobá destaca naquele a possibilidade de subjetivação, sociabilidade e identidade e neste a alienação e o estranhamento. Também o espaço urbano demonstra-se despersonalizado e anônimo; já o cenário da cidade pequena revela o fortalecimento da identidade do indivíduo e da coletividade. A intertextualidade presente se faz bastante evidente em diálogo com o discurso bíblico, imprimindo à narrativa um tom mítico que ultrapassa o seu contexto imediato histórico da década de 1970. A representação da mão do operário na fábrica urbana difere de sua recriação no cenário da oficina. Lá se dissocia da mente, obedecendo à racionalidade técnica da máquina; aqui se conjuga à mente do operário, detentor de todo o processo de criação. Ainda em relação ao espaço da metrópole, vê-se que é recriado a partir de uma linguagem descritiva e detalhada, como se o protagonista tentasse se apropriar desse espaço que lhe é estranho; já o cenário de sua cidade natal é dado de modo difuso e vago, pois é familiar, não carecendo de muitos detalhes descritivos. $\mathrm{O}$ foco narrativo 
é pendular, indo da primeira pessoa a terceira, fazendo com que do caso particularizado de Natanael, alcance-se o geral em que a situação individualizada pode ser generalizada, concretizando-se como universal.

\section{Referências}

BAKHTIN, Mikhail (1986). Marxismo e filosofia da linguagem. Tradução de Michel Lahud e Yara Frateschi Vieira. São Paulo: Hucitec.

(1988) Questões de literatura e de estética: a teoria do romance. Tradução de Aurora Fornoni Bernardini et al. São Paulo: Hucitec.

ENGELS, Friedrich (1990). O papel do trabalho na transformação do macaco em homem. 4. ed. Rio de Janeiro: Global.

LEROI-GOURHAN, André (1964). O gesto e a palavra I: técnica e linguagem. Lisboa: Edições 70 .

LUKÁCS, György (1968). Ensaios sobre literatura. 2. ed. Rio de Janeiro: Civilização Brasileira.

(1980). The ontology of social being: labour. Londres: Merlin.

JATOBÁ, Roniwalter (1979). A mão esquerda. In: Crônicas da vida operária. São Paulo: Linoart; Círculo do livro.

SENNETT, Richard (1998). The corrosion of character: the personal consequences of work in the New Capitalism. New York: Norton.

Recebido em dezembro de 2012.

Aprovado em maio de 2013.

\section{resumo/abstract}

Trabalho artesanal e trabalho industrial como elementos de sociabilidade, subjetividade e de tragédia em "A mão esquerda", de Roniwalter Jatobá

Angela Maria Rubel Fanini

Adriana Cabral

Este artigo analisa o conto "A mão esquerda", do escritor Roniwalter Jatobá, focalizando a questão do trabalho artesanal como elemento de sociabilidade, subjetividade e ontologia, e o trabalho fabril urbano como elemento de despersonalização, desagregação e tragédia. A análise se fundamenta em teóricos do romance, Bakhtin (1988), e da sociologia do trabalho, Engels (1990) e Lukács (1980), destacando a construção do es- 
paço, da linguagem, da intertextualidade, do foco narrativo e do contexto histórico.

Palavras-chave: Roniwalter Jatobá, narrativa contemporânea, trabalho artesanal, trabalho fabril, espaço urbano e rural.

Handy craft labor and industrial work as elements of sociality, subjectivity and tragedy in "A mão esquerda" by Roniwalter Jatobá

Angela Maria Rubel Fanini

\section{Adriana Cabral}

This paper investigates the short story "A mão esquerda", by the Brazilian writer Roniwalter Jatobá, focusing the handy craft labor as an element of subjectiveness, sociability and ontology and factory labor as an element of depersonalization, disagregation and tragedy. The study backgrounds on Bakhtin's theory on the novel and on Engels' (1990) and Lukács' (1980) view on human labor, analyzing language, point of view, space, intertextuality and social context.

Keywords: Roniwalter Jatobá, contemporary short story, handy craft labor, factory labor, urban and rural space. 